\title{
Diagnosis and Surgical Principles in the Treatment of Acute Injuries of the Flexor Tendons of the Hand
}

\author{
Gordana Georgieva $^{1 *}$, Tomislav Jovanoski ${ }^{1}$, Zana Aliu$^{2}$, Gjorgje Djokic ${ }^{1}$
}

Received: 06 March 2021 / Accepted: 02 April 2021 / Published online: 20 July 2021

This article is published with open access at https://journal.astes.org.al

(C) The author(s) 2021. \& Copyright (C) 2021, the Albanian Society for Trauma and Emergency Surgery

(a) The Albanian Journal of Trauma and Emergency Surgery is an Open Access Journal. All articles are distributed under the terms of the Creative Commons Attribution Non-Commercial License: http://creativecommons.org/licenses/by-nc/4.0/) which permits unrestricted non-commercial use, distribution, and reproduction in any medium provided the original work is properly cited.

\begin{abstract}
Injuries to the flexor tendons of the wrist are a separate chapter in wrist surgery. Flexor tendon injuries still remain a challenge to ensure the patient's optimal outcome.

A special problem in the exploration of hand injuries is the accurate assessment of whether there is an injury to one or more tendons, at what height the injury is, and whether it is accompanied by injury to other elements of the hand.

On the volar side of the hand, both flexors of the fingers, superficial and deep, or just one of them, maybe injured. If the lesion is in the first zone depending on the severity of the injury, reinsertion or direct tenography is required.

In the second zone, there are still ambiguous views on the reconstruction of the deep and superficial flexor, ie. whether the surface flexor needs to be reconstructed. Injury to the flexor tendons in the third zone requires careful exploration for possible injury to the neurovascular elements, and the fourth zone often requires the release of the carpal tunnel.

In the most proximal zone of the flexor tendons, the fifth zone, injury to the main blood vessels of the hand and the nerves responsible for sensitive and motor innervation of the hand is possible.

Each injury should be approached with careful preoperative examination, appropriate operative technique as well as postoperative rehabilitation in order to fully restore the function of the hand.
\end{abstract}

Keywords: flexor tendon, injury, injury zone, fist, deep, superficial

\section{Introduction}

Tendons connect the muscles to the bones to allow force to be transferred from the muscle to the bone, allowing the joint to move. There are two flexor tendons on each finger and one on the thumb.

The arm is divided into 5 zones. (fig. 1)

Zone I starts at the fingertips and ends with Zone $\mathrm{V}$ on the wrist. Zone I is distal to the insertion of the superficial

Original article, no submission or publication in advance or in parallel

* Corresponding author:

\section{Gordana Georgieva MD}

$\bowtie$ gordana_georgieva@yahoo.com

1 University Clinic for Plastic and Reconstructive Surgery-Skopje, Republic of North MACEDONIA

2 University Clinic for Traumatology, Orthopedic Diseases, Anesthesia and Resuscitation, Intensive Care and Emergency Center-Skopje, Republic of North MACEDONIA flexor; The boundaries of Zone II (no man's land) are between the shell, ie the A1 pole and the insertion of the superficial finger flexor; Zone III is at the distal edge of the transverse carpal ligament and septum A1, and covers nerves, tendons, and blood vessels that are often prone to trauma due to proximity.

Zone IV refers to the tendons within the carpal tunnel and zone $\mathrm{V}$ covers the forearm proximal to the carpal tunnel.[1]

\section{Surgical anatomy and basic principles of treatment}

Injuries to the flexor tendons of the wrist are a special chapter in wrist surgery because of their specific anatomy and physiology, possible functional outbursts, and various techniques for their repair.

Flexor tendon injuries still remain a challenge to ensure the patient's optimal outcome. Since Kirchmeier described the first repair of an injured flexor tendon in 1917, several approaches to flexor tendon injury have enabled a 
successful repair rate of $70-90 \%$. [1, 2]. For these reasons it is necessary to know the following basic principles in order to be able to make their correct reparation or reconstruction:

"Common wound" (joint wound) healing concept means that the healing process of each wound is the same, i.e., it includes all injured tissues in that area, whether it is a tendon, soft tissue, periosteum or bone injury. To understand this concept, we must remember the stages of healing of injured tendons. Namely, there are three phases of healing of injured tendons: exudative phase with elements of inflammation (the first few days), then phase of fibroplasia dominated by fibroblasts and collagen fibers that are threedimensionally placed on all injured tissues and fix each other and the last phase of remodeling and polarization of collagen fibers (third week) with fibers parallel to the direction of movement of the repaired tendon. In order to avoid the concept of "joint wound", i.e., the fusion of the injured ends of the tendons with the surrounding tissues, it is necessary for the surgical reparation of the injured tendons to be as correct as possible and by using atraumatic surgical technique and surgical materials. [3, 4].
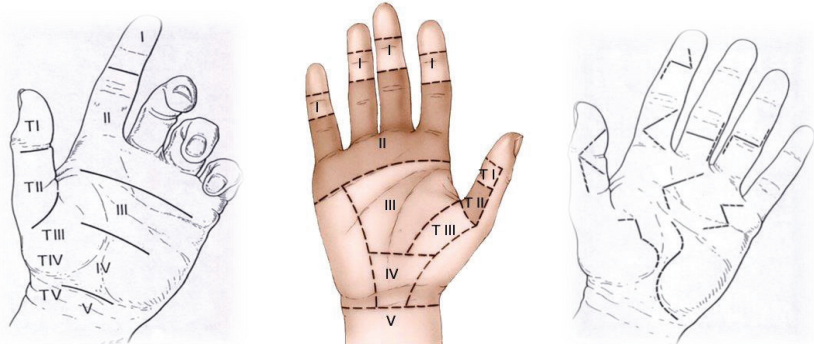

Figure 1. Zones of flexor injuries (left and middle), skin incisions for access to injuries (right)

Timing for surgical repair - the general rule is that primary tendon repair / suturing should be done in the first few hours after injury, up to a maximum of 24 hours after injury. If for any reason (poor general or local condition, infection, etc.) primary reparation is not possible, then it is delayed for 2-14 days and then delayed primary reparation is done when local conditions are good. In case of delayed reparation for the next 3-5 weeks after the injury, there is retraction and fibrosis of the injured ends and collapse of the synovial sheath.

This "short retracted tendon" is very difficult to repair, even with elongation, so early secondary reconstruction is done by removing the retracted and fibrous tendon, tenolysis and in case of impossibility of elongation with direct suture a healthy tendon is transplanted. taken from elsewhere. If more than 5 weeks have passed since the injury then late secondary reconstruction is performed by removal of fibrous and fused tendon tissue, reconstruction of the pelvis, placement of temporary tendon silicone prostheses and in the second act transplantation of a healthy tendon, usually from $\mathrm{m}$. palmaris longus. [4].

\section{Diagnosis of flexor tendon injuries}

A special problem in the exploration of hand injuries is the accurate assessment of whether there is an injury to one or more tendons, the degree of that injury, i.e., whether it is complete or partial, at what height is the injury and whether it is accompanied by injury to other elements of the hand (fig. 2). On the volar side of the hand, both flexors of the fingers, superficial and deep, or just one of them, may be injured. If, during the injury, the wrist was fully extended, then both flexors are injured at the same height as the wound, but in case of flexion injury (bent fingers), then the flexor tendons are broken at different heights and therefore their function needs to be tested. for an accurate assessment of the type and extent of the injury. $[5,6]$.

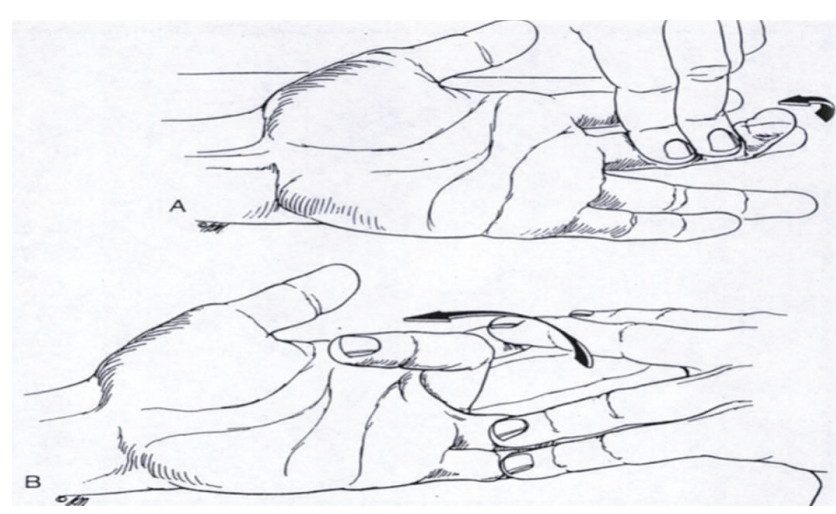

Figure 2. Deep flexor (A) and superficial flexor (B) function testing

\section{Classification according to Injury Zones}

\section{Deep flexor injuries in Zone I}

This zone extends from the middle of the medial phalanx to the tip of the fingers and here injury is possible only to the deep flexor of the fingers, which allows flexion in the distal interphalangeal joint, that is, flexion of the distal phalanx. There is an indication for primary repair of the injured deep flexor, but the surgical technique depends on the level of the lesion. If the lesion is more than $1 \mathrm{~cm}$ away from the site of insertion / digitization of the distal phalanx tendon, then mobilization of the proximal end and suture at both ends. [5, $6]$. In case the lesion is $1 \mathrm{~cm}$ or closer to the site of insertion / digitization, then mobilization and re-insertion is done at the end of the tendon for the distal phalanx using the "pullout wire \& button" technique, ie fixation and re-insertion for the distal phalanx with metal pin and wire passing through the phalanx and nail and stabilization with a plastic button on the nail.

In addition to open injuries to the deep flexor in this area, closed injuries such as augmentation or rupture of the rugger jersey finger, with or without a bone fragment of the distal phalanx, are less common. They are caused by forced hyperextension of the distal phalanx in a bent position of the 
finger with a contracted tendon, and the fourth finger usually suffers (75\%). [7]. Depending on the degree of retraction of the torn tendon, there are three types of injuries:

1. Retraction / retraction of the detached tendon to the proximal interphalangeal joint (PIP)

2. Retraction / retraction of the detached tendon to the palm area

3. Auction of a bone fragment from the distal phalanx with retraction of the tendon distal to A4.

\section{Flexor Injuries in Zone II}

Injuries to the flexor tendons in this area, which extend from the middle of the medial phalanx to the distal palmar groove, are the biggest problem and controversy for surgeons dealing with hand injuries. Bunnel called this zone "no man`s land" because in this region the two flexors are intimately placed next to each other and have a common fibrous and synovial sheath. [7, 8] A critical factor in assessing the extent of the injury is the level of injury to both flexors. If during the tendon injury the fingers were extended, ie they are cut at the same level. If the injury occurred at the moment when the fingers were flexed, ie bent, they are cut at different levels and distally from the skin injury. [8]. There are four basic types of flexor tendon injuries with their own characteristics:

1. deep flexor injury only,

2. superficial flexor injury only,

3. injuries to both flexors but at different levels

4. injuries to both flexors but at the same level.

Isolated deep flexor injury - primary repair of the injured ends is indicated by mobilization of the proximal end, sometimes a thin plastic catheter is used for mobilization which is temporarily sutured to the injured end. (fig. 3) The mobilized proximal end is temporarily fixed with a metal needle and then the sutured cut ends are made [9, 10].

Isolated superficial flexor injury - is still a dilemma among surgeons whether or not such an injury should be repaired primarily. Most surgeons believe that primary repair of the superficial flexor should still be performed for complete flexion of the proximal interphalangeal joint. [10, 11].

Injuries to both flexors at different levels - occurs when the fingers are flexed, bent at the time of injury and due to the different excursions of the two flexors, the difference in the level of their injuries is $1 \mathrm{~cm}$ or more. In these injuries there is an indication of primary repair of both flexors, as their lesions are at different levels there is little chance of mutual fusion.

When repairing, care must be taken with the integrity of the fibrous sheath rings (especially A2 and A4) for normal finger flexion. In case of injury to these "pulleys", "bowstringing" occurs, ie tendon prolapse and impaired function. [12, 13].

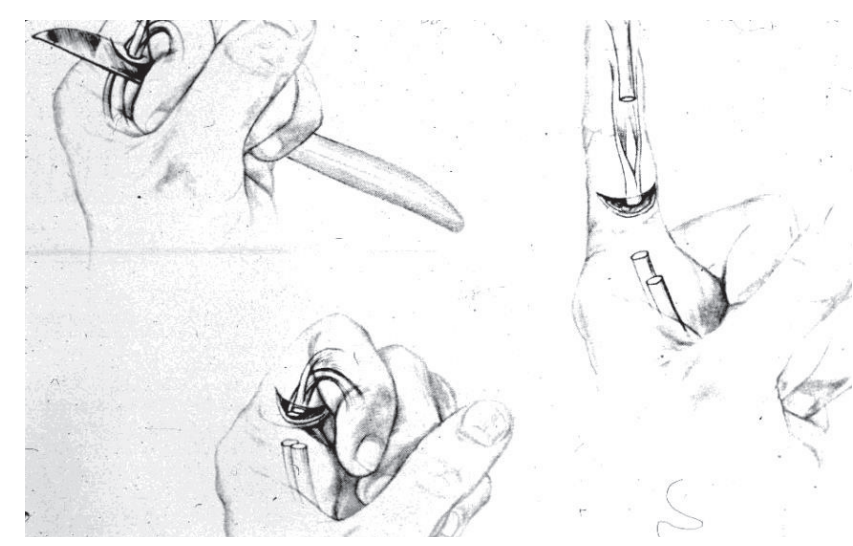

Figure 3. Injuries to both flexors at different levels with bent fingers

Injuries to both flexors at the same level - occurs when the fingers are extended, straight at the time of injury and then the level of injury to both flexors is the same or the difference is less than $1 \mathrm{~cm}$. There is still controversy over whether to repair both flexors or just the deep flexor. The problem is that when suturing the two flexors due to the similar level of injury, their mutual fusion can occur with a dominant function of the superficial flexor. For these reasons, a number of authors recommend primary repair only of the deep flexor, while the superficial flexor only reduces and leaves unsaturated, especially when it comes to concave and irregular injuries. A small number of authors, however, suggest a primary correct repair of both flexors, with preservation of the important fibrous rings, A2 and A4, especially when it comes to cuts and proper injuries. $[14,15]$.

Injury of the long thumb flexor - despite the specific anatomical structure of the thumb (only two phalanges, one flexor tendon and a small number of pulleys), the principles for primary repair of the injured flexor tendon are the same as for the other fingers.

\section{Flexor Injuries in Zone III}

This zone extends between the distal palmar groove and the transverse carpal ligament and is called "lumbar" because of the presence of lumbar muscles that are attached to the deep flexors and thus distinguish them from superficial flexors. (fig. 4) Primary reparation of both flexors is indicated by their mobilization, the proximal end of the deep flexor is "hidden" in the lumbar muscle, while the proximal end of the superficial flexor can be pulled even below the flexor retinaculum, so it must be sought and extracted for suture. [16,17] 


\section{Flexor Injuries in Zone IV}

This zone is located in the carpal tunnel, an osteo-fibrous canal through which nine flexor tendons and a nervus medianus pass. Due to the narrow and difficult-to-access tunnel, the intimate relations between the tendons and the nerve and the possibility of their combined injury, this zone is also called "enemy territory" by some authors. For better access to the injured tendons, it is sometimes necessary to make an incision of the transverse carpal ligament. Primary reparation of all injured tendons with mobilization at the ends is indicated $[18,19]$.

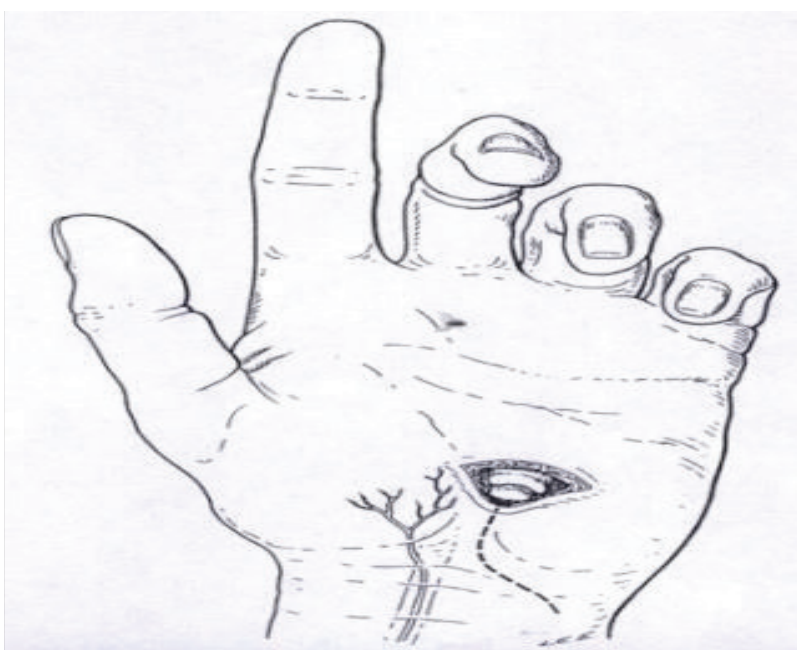

Figure 4. Flexor injuries in the fourth zone

\section{Flexor Injuries in Zone $V$}

Injuries to the flexor tendons in the wrist and distal third of the forearm (paron's space) are often multiple and combined with injuries to nerves or blood vessels, so careful exploration and accurate diagnosis are required. (fig. 5) Primary repair of all injured tendons, as well as injured nerves and blood vessels is indicated. $(19,20)$

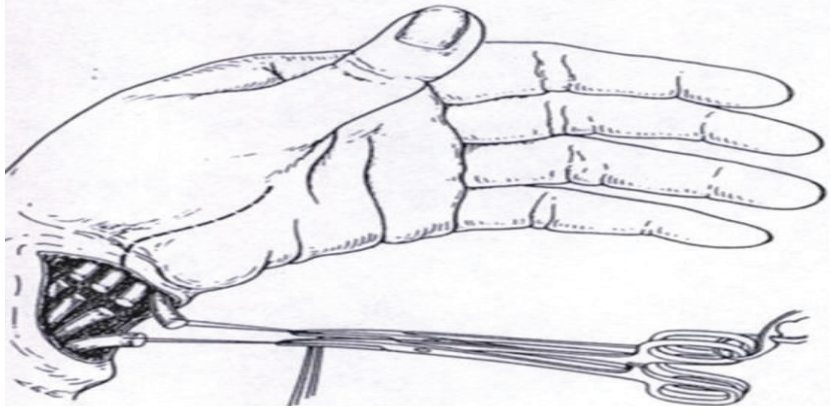

Figure 5. Flexor injury in the fifth zone

\section{Primary care and postoperative care of flexor tendons}

For reparation / suture of the injured ends of the flexor tendons, non-absorbent monofilament, nylon threads with a thickness of 3/0, 4/0 for suture of the injured ends and 5/0 or $6 / 0$ for suture of the epithenium are used. As for partial, partial flexor tendon injuries, it is recommended that they be treated conservatively if less than $40 \%$ of the tendon width is preserved, in which case surgical repair is indicated. (fig. 6) There are numerous techniques (Kessler, Kleinert, Bunnell, Strickland, Tsuge, etc.) for suturing the injured ends of tendons, and the most practiced are shown in the following drawing. (20).

After surgery, immobilization of the injured hand with a dorsal plaster cast is performed in a position of flexion of the wrist of 30-40 degrees and flexion in the metacarpophalangeal joint of 45-50 degrees and elastic fixation of the fingers through the nails with rubber bands on the volar side of the wrist. wrist. After the first 2-3 days of rest, the regime of controlled passive mobilization of the operated fingers on the principle of "active extension and passive flexion" begins, which lasts for the next threefour weeks. The immobilization and rubber bands are then removed and the patient is sent for physical therapy and rehabilitation. [18, 19, 20]

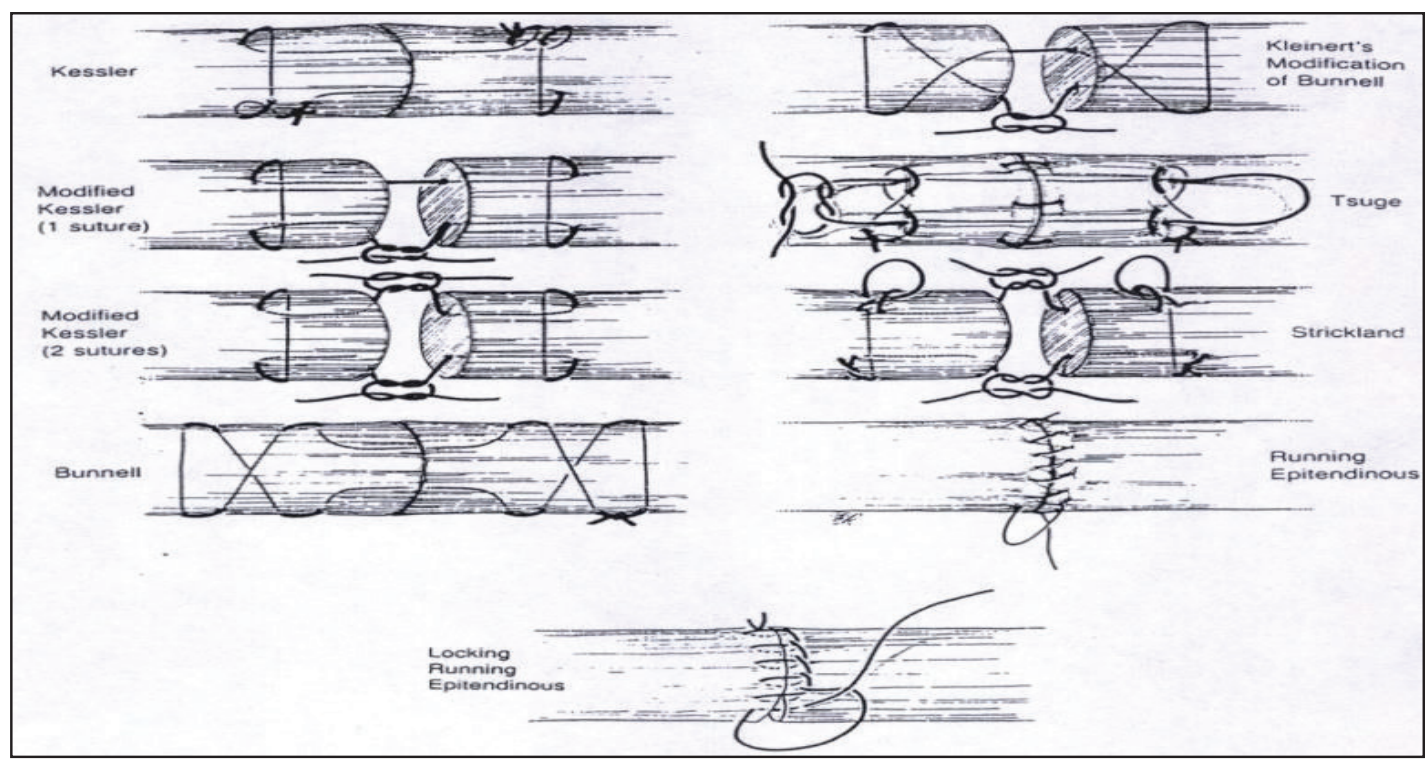

Figure 6. The most common techniques for suturing flexor tendons 


\section{Conclusion}

Treatment of injured flexor tendons is a major challenge due to the fact that the surgical procedure itself is complicated, and often paid for with poor, disappointing results. Therefore, a good knowledge of the anatomy as well as the healing process, with good surgical atraumatic technique is the basis for successful surgical treatment. Quality and well-placed tendon suture with adequate immobilization is the main prerequisite for establishing good function of the injured wrist. Digital nerve dysfunction is often present in these injuries. The results show that injuries sustained by sharp objects have a better outcome. The incidence of the male population compared to the female is almost 6: 1 . Prompt and timely surgical treatment is incomparably better than delayed reparation

COI Statement: This paper has not been submitted in parallel. It has not been presented fully or partially at a meeting or podium or congress. It has not been published nor submitted for consideration beforehand.

All authors declare that there is no conflict of interest. This research received no specific grant from any funding agency in the public, commercial, or nonprofit sectors. There are no relevant or minor financial relationships from authors, their relatives or next of kin with external companies.

\section{References}

1. Kannus P, Jozsa L, Jarvinnen M. Basic science of tendons. In: Garrett WE Jr, Speer KP, Kirkendall DT, editors. Principles and practice of orthopaedic sports medicine. Philadelphia: Lippincott Williams and Wilkins; 2000. pp. 21-37. [Google Scholar]

2. O'Brien M. Structure and metabolism of tendons. Scand $J$ Med Sci Sports. 1997; 7: 55-61. [PubMed] [Google Scholar]

3. Hess GP, Cappiello WL, Poole RM, Hunter SC. Prevention and treatment of overuse tendon injuries. Sports Med. 1989;8:37184. [PubMed] [Google Scholar]

4. Tipton CM, Matthes RD, Maynard JA, Carey RA. The influence of physical activity on ligaments and tendons. Med Sci Sports. 1975; 7: 165-75. [PubMed] [Google Scholar]

5. Jozsa LG, Kannus P. Spontaneous rupture of tendons. In: Jozsa LG, Kannus P, editors. Human tendons: anatomy, physiology, and pathology. Champaign, IL: Human Kinetics;
1997. pp. 254-325. [Google Scholar]

6. Movin T, Kristoffersen WM, Shalabi A, Gad A, Aspelin P, Rolf C. Intratendinous alterations as imaged by ultrasound and contrast medium-enhanced magnetic resonance in chronic achillodynia. Foot Ankle Int. 1998;19:3117. [PubMed] [Google Scholar]

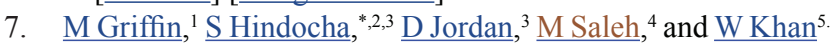
An Overview of the Management of Flexor Tendon Injuries. Open Orthop J. 2012;Suppl 1; 6: 28-35.

8. Moutiet F. Flexor tendon pulley system: anatomy, pathology, treatment. Chir Main. 2003;22(1):1-12. [마bMed] [Google $\underline{\text { Scholar] }}$

9. Green DP, Pederson WC, Hotchkiss RN, Wolfe SW, editors. Greens operative Hand Surgery. 5th. Philadelphia, Pennsylvania: Elsevier Churchill; 2005. [Google Scholar]

10. Ѓорѓе Џокиќ и сор. Заболувања и повреди на шака, Арсламина. Скопје , 2010.

11. Tillman LJ, Chasan NP. Properties of dense connective tissue and wound healing. In: Hertling D, Kessler RM, editors. Management of common musculoskeletal disorders: physical therapy principles and methods. 3rd. Philadelphia: Lippincott; 1996. pp. 8-21. [Google Scholar]

12. Ting J. Tendon injuries across the world. Injury. 2006; 37:1036-42. [PubMed] [Google Scholar]

13. Kleinert HE, Spokevicius S, Papas NH. History of flexor tendon repair. J Hand Surg Am. 1995; 20: S4652. [PubMed] [Google Scholar]

14. Bruner JM. The zig-zag volar-digital incision for flexortendon surgery. Plast Reconstr Surg. 1967;40:571. [PubMed] [Google Scholar]

15. Hall RF, Jr, Vliegenthart DH. A modified midlateral incision for volar approach to the digit. J Hand Surg Br. 1986;11(2):1957. [PubMed] [Google Scholar]

16. Strickland JW. Flexor tendon injuries: I. Foundations of treatment. J Am Acad Orthop Surg. 1995; 3:4454. [PubMed] [Google Scholar]

17. Barrie KA, Tomak SL, Cholewicki J, Wolfe SW. The role of multiple strands and locking sutures on gap formation of flexor tendon repairs during cyclical loading. J Hand Surg Am. 2000; 25:714-20. [PubMed] [Google Scholar]

18. Hatanaka H, Manske PR. Effect of suture size on locking and grasping flexor tendon repair techniques. Clin Orthop Relat Res. 2000; 375:267-74. [PubMed] [Google Scholar]

19. Manske PR, Lesker PA. Flexor tendon nutrition. Hand Clinics. 1985; 1:13-24. [PubMed] [Google Scholar]

20. Savage R, Risitano G. Flexor tendon repair using the sixstrand method of repair and early active mobilisation. J Hand Surg British. 1989; 14:369-99. [PubMed] [Google Scholar] 